AUTHOR QUERY FORM

\begin{tabular}{|l|l|l|}
\hline & Journal: AM & Please e-mail or fax your responses and any corrections to: \\
& & E-mail: corrections.essd@elsevier.sps.co.in \\
\hline ELSEVIER & Article Number: 9344 & Fax: $+\mathbf{3 1} 204852799$ \\
\hline
\end{tabular}

Dear Author,

Please check your proof carefully and mark all corrections at the appropriate place in the proof (e.g., by using on-screen annotation in the PDF file) or compile them in a separate list. To ensure fast publication of your paper please return your corrections within 48 hours.

For correction or revision of any artwork, please consult http://www.elsevier.com/artworkinstructions.

Any queries or remarks that have arisen during the processing of your manuscript are listed below and highlighted by flags in the proof. Click on the ' $Q$ ' link to go to the location in the proof.

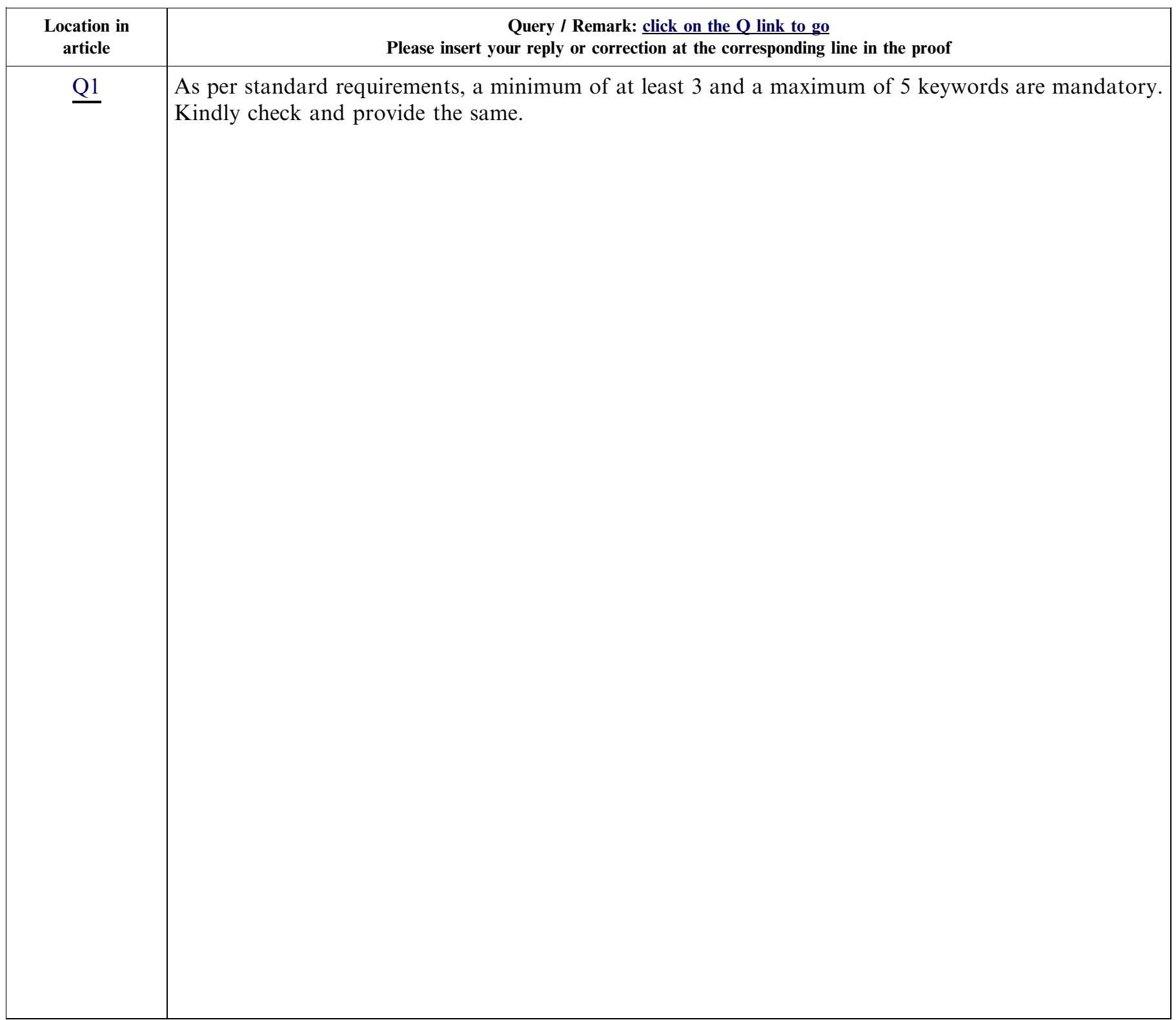

Thank you for your assistance. 


\title{
Intergranular penetration of liquid gold into stainless steel
}

\author{
D. Favez*, L. Deillon, J.-D. Wagnière, M. Rappaz \\ Laboratoire de Simulation des Matériaux, École Polytechnique Fédérale de Lausanne, Station 12, CH - 1015 Lausanne, Switzerland
}

Received 16 February 2011; received in revised form 8 June 2011; accepted 18 June 2011

\section{Abstract}

Intergranular penetration of liquid $18 \mathrm{~K}$ gold into a superaustenitic stainless steel, which occurs during laser welding of these two materials, has been studied using a C-ring device which can be put under tensile stresses by a screw. It is shown that liquid gold at $1000{ }^{\circ} \mathrm{C}$ penetrates the immersed stainless steel C-ring at grain boundaries, but only when tensile stresses are applied. Based on the thickness of the peritectic phase that forms all along the liquid crack and on the transverse gold diffusion profile in steel, penetration velocities on the order of $10 \mu \mathrm{m} \mathrm{s}^{-1}$ are deduced.

(C) 2011 Acta Materialia Inc. Published by Elsevier Ltd. All rights reserved.

Q1 Keywords: Grain boundaries penetration; Liquation

\section{Introduction}

During laser welding of gold and stainless steel for jewelry applications, it has been observed that the liquid of the molten pool, made primarily of gold, can penetrate the solid stainless steel part [1]. This occurs at grain boundaries juxtaposing the liquid pool, where the solid is under maximum tensile stresses due to thermal contraction. Typical penetration distances are $10-100 \mu \mathrm{m}$. Taking into account the interaction time with the laser beam, i.e. pulse duration, a penetration velocity on the order of $0.01-0.1 \mathrm{~m} \mathrm{~s}^{-1}$ can be estimated.

Penetration of a liquid metal at grain boundaries of a solid is found in the literature in various contexts. The thermodynamic driving force is the surface energy decrease caused by the replacement of a large misorientation grain boundary of energy $\gamma_{g b}$ by two solid-liquid interfaces of lower energy $\gamma_{s l}$, i.e. when $2 \gamma_{s l}<\gamma_{g b}$ [2-4]. However, the mechanisms of intergranular liquid penetration are still not fully understood.

\footnotetext{
* Corresponding author.

E-mail addresses: denis.favez@a3.epfl.ch(D.Favez),lea.deillon@epfl.ch (L. Deillon), jean-daniel.wagniere@epfl.ch (J.-D. Wagnière), michel.rappa z@epfl.ch (M. Rappaz).
}

Fundamental research on the underlaying mechanisms and penetration velocity is mainly related to liquid metal (induced) embrittlement (LME or LMIE). In this case, a normally ductile metal such as $\mathrm{Al}$ or $\mathrm{Cu}$ loses_its ductility when it is in contact with another metal in the liquid state, such as $\mathrm{Ga}$ or $\mathrm{Bi}[5,6]$. The liquid metal penetrates the solid at grain boundaries and dramatically decreases its mechanical properties. Numerous studies and reviews have been published on LME and several models have been developed. However, there is no single explanation or model that is generally applicable, as the mechanisms appear to vary from one system to another [7,8]. According to Glickman [9], propagation of the liquid crack is controlled by atomic reaction at the tip. Above a stress intensity threshold $K_{T H}$, propagation occurs at a fixed rate $V_{\infty}$, these two parameters being highly sensitive to the nature of the liquid metal. Recently, Klinger and Rabkin [10] proposed a mechanism in which the concentration gradient along a wetted grain boundary induces a grain boundary energy gradient. This causes a net flux of atoms towards the liquid crack tip, which accumulate and subsequently generate stresses that are able to further propagate the liquid crack. According to this mechanism, no external stress is required.

Another similar phenomenon observed during welding is related to grain boundary liquation in the so-called 
60 heat-affected zone. Because of their higher surface energy

61 or the presence of low melting temperature intermetallics

62 caused by microsegregation in the base material, grain 63 boundaries can melt at temperatures below the solidus $64[11,3]$. In the presence of tensile stresses, the liquid films 65 at grain boundaries show almost no mechanical resistance and open, thus allowing the liquid of the weld pool to penetrate. This phenomenon is thus very similar to "healed" hot tears forming during solidification, i.e. when the opening of grain boundaries by tensile stresses that normally leads to hot cracks can be fed by interdendritic or intergranular liquid [12,13].

One particular case of the presence of liquid metal at the grain boundaries of steel is associated with copper. Copper can be present in steel as impurities, especially when recycling car bodies which contain copper electric wires, or when welding is performed with copper-containing fixtures or tools around the welds. During welding or hot rolling, copper can penetrate along grain boundaries in some austenitic or structural steels. This leaves an intergranular solid copper film that dramatically decreases both the base metal strength and ductility at high temperature. The "hotshortness" induced by the presence of copper at grain boundaries is thus called copper contamination cracking (CCC). The CCC is accelerated by external or residual stresses [14-16], but no detailed mechanism has been given in the literature.

Experimental characterization of these phenomena is usually related to a specific application. In the case of LME, the loss of mechanical properties is of major concern. Therefore, tensile or compression tests at room temperature are conducted after penetration [17,18], while in situ experiments using transmission electron microscopy or X-ray microtomography give insights into the underlaying mechanisms $[5,19]$. Several tests are commonly used to characterize the liquation cracking susceptibility during welding. One of them, the nil-ductility test, focuses on the temperature at which the ductility of a specimen falls to zero [20].

The aim of the present study was to better understand the origin of liquid gold penetration into stainless steel during laser welding. In transverse cross-section of the welds, liquid penetration appears mainly in regions at about $45^{\circ}$ between the weld centerline and the top surface of the steel side. Since this location also corresponds to maximum tensile stresses during welding, it was conjectured that penetration of liquid gold into solid steel requires a tensile stress state of the solid material. In order to test this hypothesis at temperatures at which liquid gold is in contact with solid steel (i.e. temperature in the range 900$1350{ }^{\circ} \mathrm{C}$ ) a new specific setup had to be developed, as standard LME tests are not applicable.

\section{Experiment}

With this objective in mind, a so-called "C-ring test" was selected (Fig. 1). It is a standard stress-corrosion test

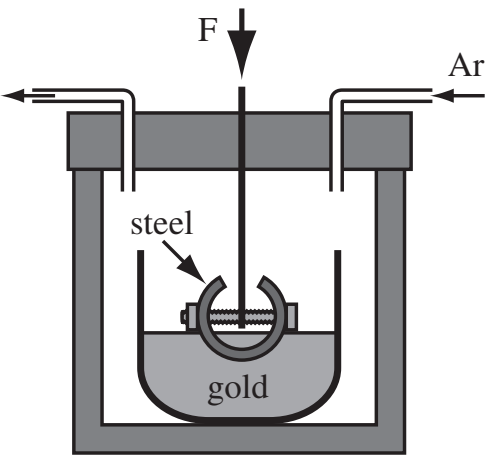

Fig. 1. Experimental C-ring setup. The inner/outer diameters of the C-ring are $20 / 24 \mathrm{~mm}$; its thickness is $20 \mathrm{~mm}$.

in which a specimen with a "C" shape can be stressed by a screw parallel to the opening of the "C" (see the figure). At the symmetry plane of the C-ring, the hoop stress component $\sigma_{\theta \theta}$ is tensile at the outer surface while it is compressive at the inner surface [21]. Furthermore, the tensile component varies from zero at the location of the screw to a maximum at the symmetry plane of the C-ring, this maximum being adjusted by the compression (or radial stress) component at the screw location. Besides stress-corrosion cracking, such a test has also been used to study the penetration at room temperature of steel or aluminum by mercury [22,23]; however, to the best of our knowledge, no application has been made at elevated temperature. One of the reasons for this is that, at high temperature, the C-ring material (and possibly the screw itself) may creep, thus partially releasing the imposed stress [24]. The initial imposed stress level was found to be not so important, as long as the screw was tightened (even by hand only) at room temperature. During heating, some additional stress could be induced by differential thermal expansion of the screw and C-ring. However, the behavior of steel at the temperature of the liquation test $\left(1000^{\circ} \mathrm{C}\right.$, i.e. about $2 / 3$ of the melting point) is such that creep becomes dominant. Thus, the remaining stress in the C-ring is also a function of the strain rate, which itself depends on the penetration speed. In any case, if only partially released, the hoop stress component remains compressive/tensile inside/outside the C-ring and increases from the screw to the symmetry plane. This test can provide qualitative information on the effect of stress on liquid gold penetration.

The simple testing procedure using the C-ring was as follows: a crucible containing gold and a steel C-ring, precleaned with Ridoline, were placed in a furnace at $1000{ }^{\circ} \mathrm{C}$, under an argon flux. After melting and homogenization of the melt, the C-ring was immersed in liquid gold for a given time. The sample was then withdrawn and quenched in air. The bath was a classical 18 carat yellow gold $(\mathrm{Au}-12.5 \mathrm{wt} . \% \mathrm{Ag}-12.5 \mathrm{wt} . \% \mathrm{Cu})$ and the $\mathrm{C}$-ring was a superaustenitic 904L stainless steel.

For metallographic observations, the samples were sectioned and polished using $\mathrm{SiC}$ papers down to $1 \mu \mathrm{m}$, and were then observed by scanning electron microscopy 
(SEM) and optical microscopy (OM). To reveal the grain boundaries of stainless steel in OM, the specimens were then electro-etched in $10 \%$ oxalic acid. For one specimen, a cylinder of $600 \mu \mathrm{m}$ diameter was machined near the symmetry plane of the C-ring using electrical discharge machining. It was then analyzed by X-ray microtomography at the European Synchrotron Radiation Facility (ESRF, Grenoble, France).

\section{Results}

A typical liquid gold crack occurring at the bottom of the $\mathrm{C}$-ring is shown in Fig. 2a. It always starts at a region of maximal tensile stress, i.e. at the outer bottom surface of the C-ring, and then propagates through its whole width and thickness, as shown by X-ray microtomography (see Fig. 2c). Indeed, as the tensile stress at the outer surface of the C-ring is released by liquid penetration, the stress state at the crack tip remains tensile as long as the radial stress at the level of the screw remains compressive. The penetration path is essentially radial, but follows grain boundaries that are closest to this direction. At the free bottom surface of the specimen (top of Fig. 2a) as well as all along the liquid crack, an intermediate phase forms (see details afterwards). It should be pointed out that liquid crack initiation is not immediate and varies from one sample to another. This is probably linked with the time required to dissolve the oxide skin at the surface of the specimen, despite the Ridoline pretreatment.

When a stressed sample is heated up to $1000^{\circ} \mathrm{C}$ but without immersion in gold, no crack occurs. More interestingly, when an unstressed sample is immersed in the gold bath, there is also no penetration. However, strong solutal remelting [25] is observed at the surface of the steel in this case, with the simultaneous formation of the intermediate phase at the steel-gold interface, as shown in Fig. $2 b$. The unmelted steel is at the bottom (black region), while the quenched gold liquid (light region) is on top of the intermediate phase (intermediate grey level). Gold liquid penetration still occurs along grain boundaries (light gray lines appearing in between the intermediate grey level regions) but, unlike in the stressed specimen, this remains at the local scale (typically $10 \mu \mathrm{m}$ ) of the gold-steel interface. A few intermediate phase particles are visible in the quenched liquid, probably due to their movement when quenching the specimen.

Fig. 3a shows an enlarged view of the intermediate phase region (light gray region), surrounded by the quenched gold liquid (light region), with the dark grey austenite phase on the left. This intermediate phase has all the characteristics of a peritectic phase [13]. The arrow with the 12 markers indicates points where energy-dispersive X-ray analysis (EDX) measurements were performed, starting in the quenched liquid gold phase and ending in austenite. The measured solute profiles of the six main elements ( $\mathrm{Au}, \mathrm{Ag}$ and $\mathrm{Cu}$ for the 18-carat gold, $\mathrm{Fe}, \mathrm{Ni}$ and $\mathrm{Cr}$ for stainless steel) involved in the $\mathrm{C}$-ring test are shown in
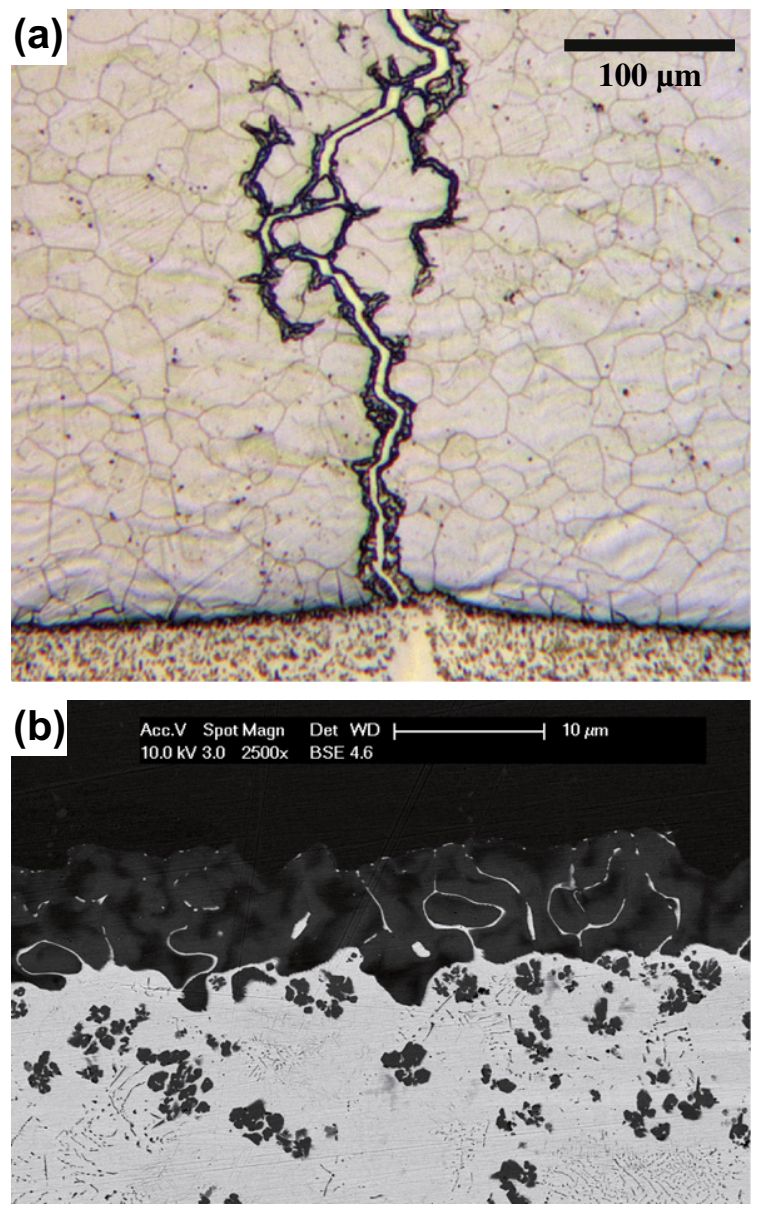

(c)

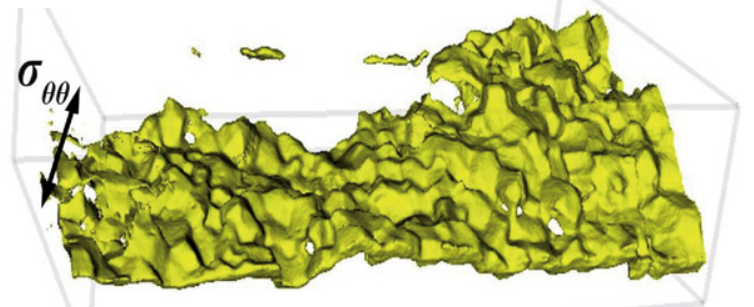

Fig. 2. (a) OM image of liquid gold penetration at stainless steel grain boundaries under an applied stress. An intermediate reaction occurs at the $s-l$ interface, leading to the formation of an intermediate phase. (b) Backscattered electron (BSE)-SEM image of a gold-steel interface of an unstressed specimen showing the formation of the intermediate phase. The steel, intermediate phase and gold appear dark, intermediate gray and light gray, respectively. (c) Three-dimensional image of the gold liquation crack surface, as reconstructed from X-ray microtomography observations.

Fig. 3b. Focusing our attention on the main constituents, i.e. $\mathrm{Au}$ and $\mathrm{Fe}$, point 1 is close to the nominal composition of 18-carat gold ( 70 instead of $75 \mathrm{wt} . \% \mathrm{Au}$ ). The Au composition is nearly constant in the quenched gold liquid phase (points 2 and 3) and then suddenly decreases to about $10 \mathrm{wt} . \%$ in the intermediate phase (point 4). It experiences a slight decrease in this phase, down to $8.5 \mathrm{wt} . \%$ at point 9. In the austenite phase (points 10-12), the gold 
(a)

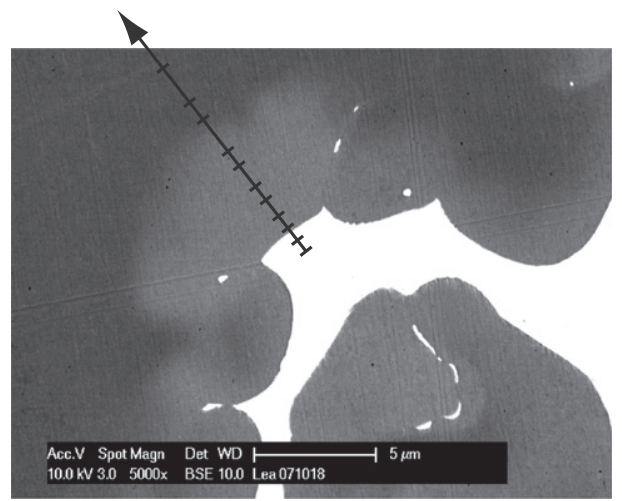

(b) 8

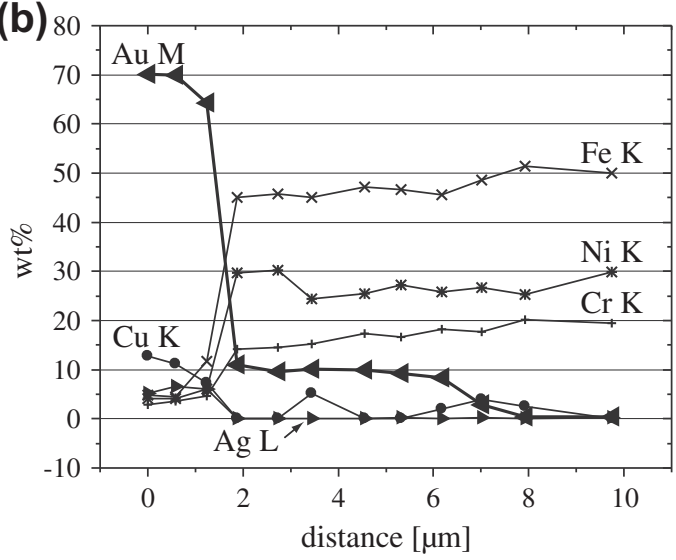

Fig. 3. (a) Enlarged BSE-SEM view of the intermediate phase (intermediate gray level), in between the quenched liquid gold (light region) and the dark austenite. The arrow with 12 markers indicates where EDX measurements were performed. The measured profiles at those points for $\mathrm{Au}(\triangleleft), \mathrm{Cu}(\bullet), \mathrm{Ag}(\bullet), \mathrm{Fe}(\times), \mathrm{Ni}(*)$ and $\mathrm{Cr}(+)$ are shown in (b).

composition exhibits a small diffusion profile. The Fe composition shows a reverse profile, starting at about $5 \mathrm{wt} . \%$ in the quenched gold liquid and ending at $50 \mathrm{wt} . \%$ in the austenite. For the minor elements, nickel and chromium show the same tendency as iron, while silver, and to some extent copper, do not diffuse much into the intermediate or austenite phases.

Using BSE, the gray level in the austenite phase in Fig. 3a directly reflects the amount of gold [26]. Thus, the brightness level profile measured at various locations

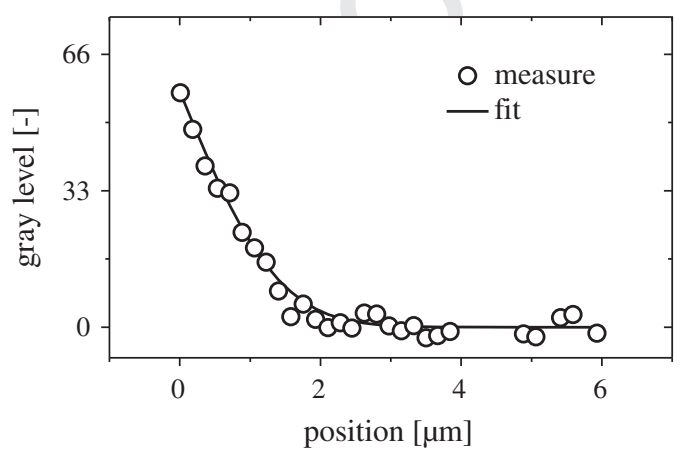

Fig. 4. Example of concentration profile used to estimate the time allowed for Au-diffusion (sample 7).

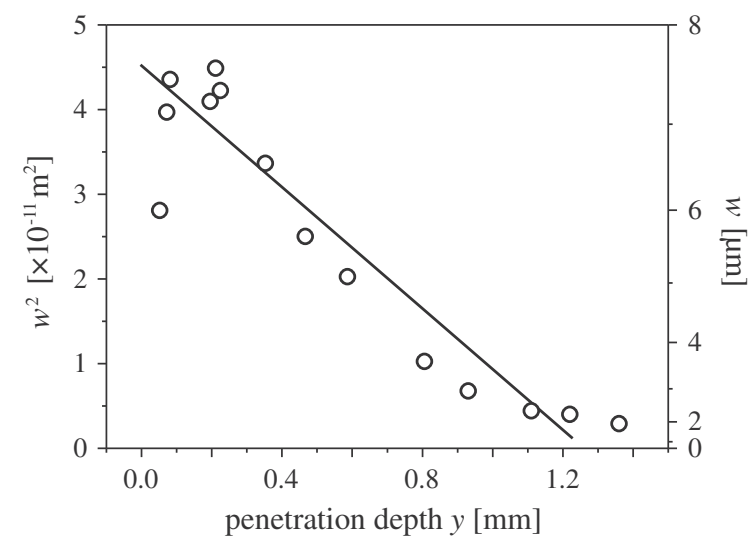

Fig. 5. Width of the peritectic phase at various positions along the penetration path (sample 7)

within the austenite phase, perpendicular to the interface, can be used to deduce the Au solute layer. Such a measurement is shown in Fig. 4, with a complementary error function fitted to the measured points. Such a profile allows the deduction at a given location of the time of contact between austenite and liquid gold. Repeated at various lengths along the gold-filled crack, such $\mathrm{Au}$ profile measurements in austenite provides a first method of estimating the speed at which liquid gold penetrates the austenite grain boundaries (see next section).

A second method is provided by the thickness of the intermediate phase (light grey region in Fig. 3a). As shown in Fig. 5, this thickness varies along the length of the goldfilled crack: from about 7 to $8 \mu \mathrm{m}$ close to the outer C-ringliquid interface (where tensile stresses apply) it is only about $2 \mu \mathrm{m}$ at the mid-thickness of the C-ring (i.e. at about $1 \mathrm{~mm}$ from the outer $\mathrm{C}$-ring-liquid interface). In this figure, the square of the intermediate phase thickness $w^{2}$ is shown on the left scale as a function of the penetration depth $y$, while the correspondence to $w$ in microns is displayed on the right scale. This $w^{2}-y$ diagram is used to show the usual dependence of $w\left(\sqrt{t_{c}}\right)$, where the diffusion time $t_{c}$ is given by $y / v$, where $v$ is the penetration velocity of the gold-rich liquid.

\section{Discussion}

In order to understand the liquid-gold-assisted liquation of austenite grain boundaries, it is necessary to first consider the thermodynamics, and thus the phase diagram, of the system. As there is no phase diagram available for this six-element system, we will discuss the results with the help of the binary $\mathrm{Au}-\mathrm{Fe}$ phase diagram of the two main constituents (see Fig. 6a $[27,28]$ ), but with some consideration of the effects of the other solute elements. First, since the $904 \mathrm{~L}$ stainless steel is austenitic, we discard the high- and low-temperature ferritic single-phase regions. Second, as the liquidus of 18 -carat gold is about $900{ }^{\circ} \mathrm{C}$, i.e. about $164{ }^{\circ} \mathrm{C}$ below the melting point of pure gold, the peritectic invariant observed at $1173{ }^{\circ} \mathrm{C}$ in the binary 


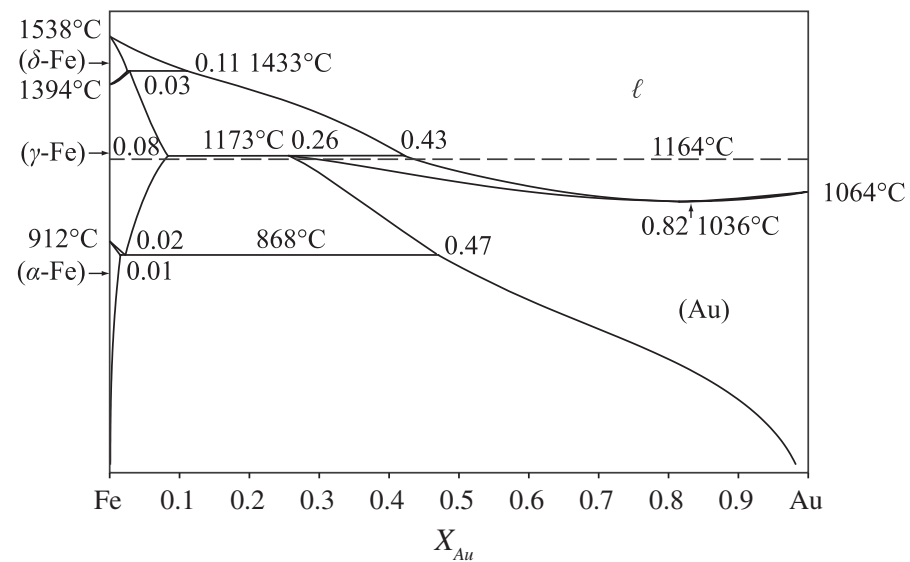

(a)

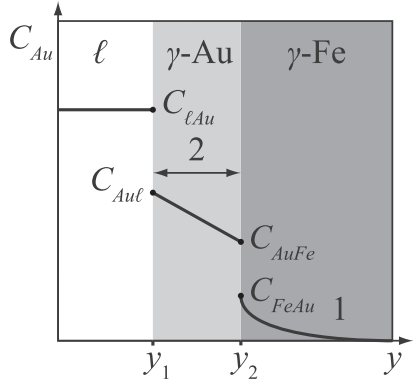

(b)

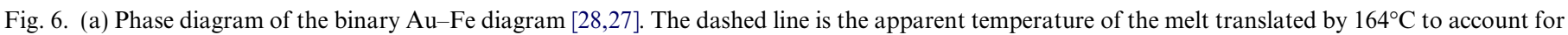

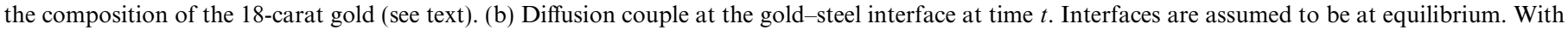
time, the concentration profile in $\gamma$-Fe evolves according to Eq. (1) and the width of the peritectic phase $w$ increases as stated by Eq. (4).

$\mathrm{Au}-\mathrm{Fe}$ system is also assumed to occur $164^{\circ} \mathrm{C}$ lower, i.e. at $1009^{\circ} \mathrm{C}$, in the case of the 18 -carat gold-steel system. Alternatively, a dashed line in Fig. 6a has been drawn $164{ }^{\circ} \mathrm{C}$ higher than the bath temperature of the C-ring test, i.e. at $1164{ }^{\circ} \mathrm{C}$. Although its position is debatable, it must be below the invariant temperature (in this case only $9{ }^{\circ} \mathrm{C}$ below) in order to explain the formation of the intermediate (peritectic) phase between the austenite and the quenched liquid. On the other hand, as the composition of gold within the peritectic phase is fairly uniform (see Fig. 3b), it must also be close to the peritectic temperature.

Based on the experimental results and with the help of the $\mathrm{Au}-\mathrm{Fe}$ binary phase diagram, a mechanism for the initiation and propagation of grain boundary liquation can be proposed. When liquid gold comes into contact with stainless steel, solutal remelting occurs together with the formation of a peritectic phase. Therefore, liquid gold must dissolve iron, while gold diffuses into solid austenite and the peritectic phase nucleates and forms in between. This explains the grey-level contrast of the various phases seen in the BSE pictures of Figs. $2 \mathrm{~b}$ and $3 \mathrm{a}$. Remelting can progress faster at grain boundaries, since the diffusion of gold is faster than in the bulk, and the remelting of grain boundaries occurs earlier because of their high energy. This explains the formation of a liquid gold film, especially at high energy grain boundaries, in both stressed and unstressed specimens.

The dramatically enhanced penetration of gold at grain boundaries of stressed specimens is still not fully understood: it could be due to enhanced diffusion, as suggested by Klinger [10], but also to liquid suction in the crack during crack opening. Indeed, as the liquid gold enters into contact with a new steel grain boundary, the peritectic phase forms while the liquid becomes enriched or even saturated with iron (nickel and chromium being omitted for the sake of clarity). When no tensile stress is applied, this is a purely diffusive process that is controlled by the rate at which new "fresh" unsaturated liquid gold reaches the grain boundary. However, tensile stress, which is intensified at the tip of the liquid-filled crack, combined with dissolution of iron into the liquid at the crack tip, makes it move forward while the two sides of the crack open more. This sucks new liquid by convection, dramatically enhancing the apparent diffusion coefficient of gold along the grain boundaries. The path follows grain boundaries, because the replacement of a large-misorientation grain boundary in austenite by two solid-liquid interfaces with a partially iron-saturated gold liquid is energetically favorable. However, if the grain boundary energy determines the local path of the crack, its overall propagation is mainly driven by the stress state in order to release the maximum strain energy.

Based on SEM-EDX image analysis, two fairly simple estimations of the liquid gold penetration velocity can be conducted for the C-ring test. Looking at Fig. 6b, which is a sketch of the transverse profile shown in Fig. 3, the peritectic phase is exactly like a diffusion couple: it is located between the liquid phase and the $\gamma$-austenite phase. Note that the peritectic phase, labeled $\gamma$-Au in Fig. 6(b), is also face-centered cubic. Interesting solid-state transformations in the $\mathrm{Au}-\mathrm{Fe}$ system (e.g. continuous and discontinuous precipitation) occurring below the peritectic temperature have been analyzed in Refs. $[1,26]$. Neglecting the time for nucleation of the peritectic phase (since it propagates along the crack boundaries), the thickness of the peritectic $\gamma$-Au phase (Fig. 5) and the width of the $\mathrm{Au}$ diffusion profile in the austenite phase (Fig. 4) can both be used to estimate the time allowed for Au-diffusion, i.e. the time separating the end of the experiment minus the time at which the liquid gold reached the position of the sample where the transverse profile is analyzed. Considering the time for diffusion at several known positions along the crack, the propagation velocity of the crack can be deduced. 
The assumptions made for these two types of calculations are as follows:

- The two interfaces $\gamma$-Fe $/ \gamma$-Au and $\gamma$-Au/liquid are at equilibrium and their kinetics is only driven by solute diffusion.

- The composition $C_{\ell \mathrm{Au}}$ in the liquid is uniform (i.e. complete mixing), considering the fast diffusion in the liquid and the width of the crack (i.e. large Fourier number).

- The formation of the peritectic phase is instantaneous once liquid gold reaches a position.

- The compositions at the two interfaces, $C_{\text {lAu }}, C_{\text {爷u }}$, $C_{\mathrm{AuFe}}$ and $C_{\mathrm{FeAu}}$ are given by the EDX measurements (see Fig. 3b and Table 1). They are constant over time.

- The Au-profile in austenite is not affected by the movement of the $\gamma-\mathrm{Au} / \gamma \mathrm{Fe}$ interface.

- The initial conditions at a given location are: no gold in the austenite phase, thickness of the peritectic phase arbitrarily small and liquid composition given by $C_{\ell} \mathrm{Au}$. Even though the diffusion of gold into austenite and the formation of the $\gamma$-Au peritectic phase gradually pumps gold from the liquid and could possibly lead to the solidification of the crack region, it is assumed that the flow of fresh liquid gold induced by the opening of the crack is sufficient for the liquid phase to always remain.

- Preferential diffusion along grain boundaries of the $\gamma-\mathrm{Fe}$ and $\gamma$-Au phases and perpendicular to the crack is not considered - or, more specifically, since the diffusion coefficient at grain boundaries is unknown, it is included in an averaged bulk diffusion coefficient, which is not accurately known.

Under these hypotheses, the first method, based on the diffusion profile of $\mathrm{Au}$ in the austenite phase, is based on the standard diffusion equation into a semi-infinite medium:

$C\left(y, t_{c}\right)=C_{\mathrm{FeAu}} \operatorname{erfc}\left(\frac{y}{2 \sqrt{D_{\mathrm{Fe}} t_{c}}}\right)$

where $y$ is the transverse distance in the $\gamma$-Fe phase measured from the $\gamma-\mathrm{Fe} / \gamma-\mathrm{Au}$ interface, $t_{c}$ is the time allowed for diffusion, in this case the time of contact between liquid gold and austenite, $\operatorname{erfc}(u)$ is the complementary error function and $D_{\mathrm{Fe}}$ the interdiffusion coefficient of $\mathrm{Au}$ in the $\gamma-\mathrm{Fe}$ phase. From the concentration profile of gold in austenite (see Fig. 4), Eq. (1) allows the time $t_{c}$ to be deduced if one knows $D_{\mathrm{Fe}}$. Repeating this measurement at various distances along the gold-filled crack gives the speed of liquid penetration.

The second model is based on the diffusion couple that forms during the peritectic reaction, more precisely on

Table 1

Interfacial compositions of $\mathrm{Au}$ (in wt.\%).

\begin{tabular}{llll}
\hline$C_{\ell \mathrm{Au}}$ & $C_{\mathrm{Au} \ell}$ & $C_{\mathrm{AuFe}}$ & $C_{\mathrm{FeAu}}$ \\
\hline 70 & 11 & 8.5 & 2.5 \\
\hline
\end{tabular}

the thickness $w\left(t_{c}\right)$ of the $\gamma$-Au phase. Assuming that the interfacial compositions are fixed (see Table 1), the two interfacial solute balances while diffusion of gold is occurring are given by:

$$
\begin{aligned}
\frac{d y_{1}}{d t}= & \frac{-D_{\mathrm{Au}}}{C_{\mathrm{Au} \ell}-C_{\ell \mathrm{Au}}}\left(\frac{C_{\mathrm{AuFe}}-C_{\mathrm{Au} \ell}}{y_{2}-y_{1}}\right) \\
\frac{d y_{2}}{d t}= & \frac{1}{C_{\mathrm{FeAu}}-C_{\mathrm{AuFe}}}\left[-D_{\mathrm{Fe}}\left[\frac{d C}{d y}\right]_{y_{2}}\right. \\
& \left.+D_{\mathrm{Au}}\left(\frac{C_{\mathrm{AuFe}}-C_{\mathrm{Au} \ell}}{y_{2}-y_{1}}\right)\right]
\end{aligned}
$$

where $y_{1}(t)$ and $y_{2}(t)$ are the positions of the two interfaces on each side of the $\gamma$-Au peritectic phase (see Fig. 6b). We have assumed that the $\mathrm{Au}$-solute profile in the peritectic phase is linear, while the gradient of $\mathrm{Au}$ in the austenite phase at the interface $y_{2}$ can be deduced from Eq. (1). Subtracting Eq. (2) from Eq. (3) gives the evolution law of the thickness $w(t)=\left(y_{2}(t)-y_{1}(t)\right)$ :

$\frac{d w}{d t}=\frac{a}{w(t)}+\frac{b}{\sqrt{t}}$

with

$$
\begin{aligned}
& a=D_{\mathrm{Au}}\left(C_{\mathrm{AuFe}}-C_{\mathrm{Au} \ell}\right)\left(\frac{1}{C_{\mathrm{FeAu}}-C_{\mathrm{AuFe}}}+\frac{1}{C_{\mathrm{Au} \ell}-C_{\ell \mathrm{Au}}}\right) \\
& b=\sqrt{\frac{D_{\mathrm{Fe}}}{\pi}} \frac{C_{\mathrm{FeAu}}}{C_{\mathrm{FeAu}}-C_{\mathrm{AuFe}}}
\end{aligned}
$$

The first term on the right-hand side of Eq. (4) is the driving force for diffusion across the peritectic phase and is proportional to the composition difference $\left(C_{\mathrm{Au} \ell}-C_{\mathrm{AuFe}}\right)$. In the binary phase diagram of Fig. 6a, this $\mathrm{Au}$ composition difference is the length of the segment on the dashed line between the $\gamma$-Au solidus and the $\gamma$-Au solvus.

The second term in Eq. (4) slows down the growth of the peritectic phase by diffusion in the austenite. Setting the initial condition $w(0)=0$, Eq. (4) admits the particular solution:

$w(t)=\left(\sqrt{b^{2}+2 a}+b\right) \sqrt{t}$

A more general solution, with any arbitrary initial condition, can be found with Mathematica ${ }^{\circledR}$, but it is then implicit and quite complex.

While the first method is only dependent on the value of $D_{\mathrm{Fe}}$, the second one, based on the thickness of the peritectic phase, is a function of both $D_{\mathrm{Au}}$ and $D_{\mathrm{Fe}}$. Indeed, when $a \gg b^{2}$ (i.e. $D_{\mathrm{Au}} \gg 0.1 D_{\mathrm{Fe}}$, using values from Table 1 ), Eq. (5) can be simplified to $w(t) \approx \sqrt{2 a t}$, in which $w(t)$ is independent of $D_{\mathrm{Fe}}$.

Furthermore, an estimation of these diffusion coefficients is not straightforward, as the self-diffusion coefficients of $\mathrm{Au}$ and $\gamma-\mathrm{Fe}$ at $1000{ }^{\circ} \mathrm{C}$ (resp. $10^{-13} \mathrm{~m}^{2} \mathrm{~s}^{-1}$ and $10^{-16} \mathrm{~m}^{2} \mathrm{~s}^{-1}$ ) are different by three orders of magnitude, making the classical Boltzmann-Matano analysis unapplicable [29]. Fig. 7 shows the penetration velocity of liquid 


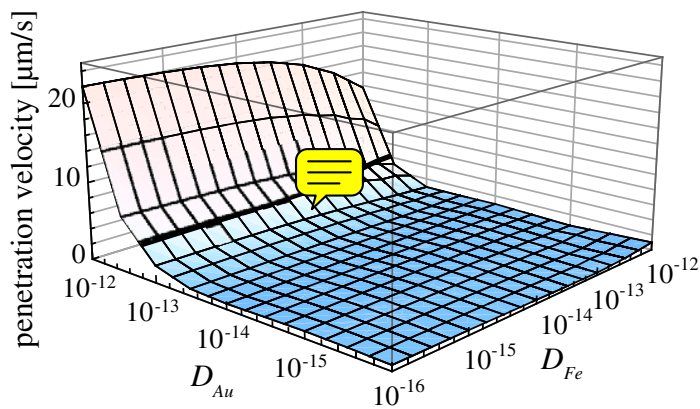

Fig. 7. Calculated penetration velocity as a function of $D_{\mathrm{Au}}$ and $D_{\mathrm{Fe}}$ for sample 7.

gold deduced for one of the C-ring specimens using this second method, as a function of both diffusion coefficients. This two-dimensional plot is only theoretical since the time is limited by the total time of the experiment. Knowing that the whole thickness of the C-ring is $2 \mathrm{~mm}$ and that the total immersion time of this specimen is $480 \mathrm{~s}$, a minimum velocity of $4.17 \mu \mathrm{m} \mathrm{s}^{-1}$ is first deduced (line drawn in Fig. 7). On the other hand, a maximum bound of this velocity has been set by considering realistic values of the solid-state diffusion coefficients $\left(D=10^{-12} \mathrm{~m}^{2}\right.$ [29]). Therefore, a realistic value of the gold liquid velocity at austenite grain boundaries can be obtained for $D_{\mathrm{Au}}=10^{-12}-10^{-13} \mathrm{~m}^{2} \mathrm{~s}^{-1}$. A value of $D_{\mathrm{Au}}=3 \times 10^{-13} \mathrm{~m}^{2} \mathrm{~s}^{-1}$ was selected for this second method.

Using this coefficient, the liquid penetration velocity deduced from the peritectic thickness at various positions along the liquid-filled crack becomes a weakly dependent function of $D_{\mathrm{Fe}}$. It is shown for two specimens with open circles and triangles in Fig. 8. The corresponding filled symbols for the same specimens have been obtained with the austenite diffusion profiles method (i.e. the results for sample 7 are calculated with data from Fig. 4 and Eq. (1) for method 1 and data from Fig. 5 and Eq. (4) for method 2). Reasonable agreement between the two methods is obtained for $D_{\mathrm{Fe}}=3 \times 10^{-14} \mathrm{~m}^{2} \mathrm{~s}^{-1}$. With such values, the penetration velocity of gold is only a few microns per

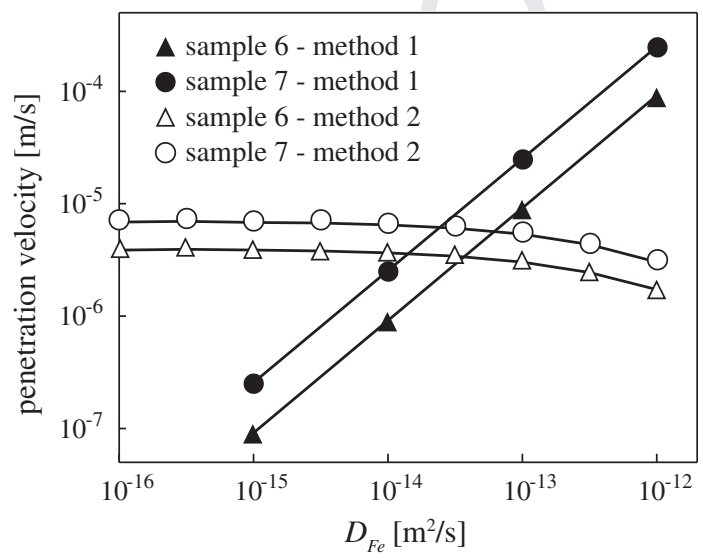

Fig. 8. Calculated penetration velocities as a function of $D_{\mathrm{Fe}}$ for two samples $\left(D_{\mathrm{Au}}=3 \times 10^{-13} \mathrm{~m}^{2} \mathrm{~s}^{-1}\right.$ for method 2$)$. second. This value is considerably smaller than that associated with laser welding $[1,26]$. Indeed, in laser welding, gold cracks of typically $10-100 \mu \mathrm{m}$ have been observed in the regions of maximum tensile strains. Considering the solidification time associated with spot laser welding (a few milliseconds), a velocity in the range $0.01-0.1 \mathrm{~m} \mathrm{~s}^{-1}$ can be deduced. This large discrepancy is probably due to the much larger stresses/strains involved in this process compared to the C-ring test.

\section{Conclusion}

A new setup has been proposed for the study of intergranular penetration of a liquid metal, in this case gold, into a solid subjected to tensile stresses, in this case a C-ring made of superaustenitic stainless steel. It has been shown that, without tensile stresses, remelting is localized at the C-ring-liquid interface. When the C-ring is compressed by a screw, liquid penetration occurs along grain boundaries, starting from the region under maximum tensile stresses and propagating inward. Measuring the thickness of the peritectic phase and of the gold diffusion profile in austenite, a penetration velocity in the range of a few microns per second has been deduced. This value is much lower than that occurring during laser welding, probably as a result of a much less severe stress state. Although the C-ring offers a very interesting mean of observing and understanding grain boundary liquation, more accurate measurements are required: (i) to obtain reliable diffusion coefficients in the phases; (ii) to eliminate any "offset" times associated with the possible formation of an oxide layer at the surface of the C-ring prior to its immersion; and (iii) to know the precise stress state of the $\mathrm{C}$-ring. The component itself, as well as the compressive screw, certainly creep during the test, thus releasing part of the stress imposed before the immersion test. High-temperature gauges could be used to eliminate this problem.

\section{Acknowledgements}

Electron microscopy analyses were performed at the CIME, Interdisciplinary Centre for Electron Microscopy (EPFL). The authors are grateful to all staff members of the ID 19 beamline of ESRF for assistance with X-ray tomography experiments, within the framework of the project ANR-05-BLAN-0286-01 TOMOSOLIDAL supported by the Agence Nationale de la Recherche.

\section{References}

[1] Favez D. PhD thesis. Lausanne: Swiss Federal Institute of Technology; 2009.

[2] Easterling KE. Introduction to the physical metallurgy of welding. London: Butterworth; 1983.

[3] Rappaz M, Jacot A, Boettinger WJ. Metall Mater Trans A 2003;34:467

[4] Takashima M, Wynblatt P, Adams BL. Interface Sci 2000;8:351. 
[5] Pereiro-Lopez E, Ludwig W, Bellet D, Lemaignan C. Acta Mater 2006:54:4307.

[6] Laporte V, Wolski K, Berger P, Terlain A, Santarini G. Diffus Defect Data A 2005;237-240:683.

[7] Fernandes PJL, Jones DRH. Int Mater Rev 1997;42:251.

[8] Joseph B, Picat M, Barbier F. EPJ Appl Phys 1999;5:19.

[9] Glickman EE. Interface Sci 2003;11:451.

[10] Klinger L, Rabkin E. Acta Mater 2010;62:918.

[11] Kou S, Savage WE. Welding metallurgy. 2nd ed. Hoboken (NJ): Wiley; 2002.

[12] Campbell J. Castings. 2nd ed. Oxford: Butterworth-Heinemann; 2003.

[13] Dantzig JA, Rappaz M. Solidification. Lausanne: EPFL Press; 2009.

[14] Lippold JC, Kotecki DJ. Welding metallurgy and weldability of stainless steels. 5th ed. Hoboken (NJ): Wiley; 2005.

[15] Nippes EF, Ball DJ. Welding J 1982;61:75s.

[16] Savage WF, Nippes EF, Mushala MC. Welding J 1978;57:145.

[17] Ina K, Koizumi H. Mater Sci Eng A 2004;387-389:390.

[18] Kozlova, Rodin A. Diffus Defect Data A 2006;249:231.
[19] Hugo RC, Hoagland RG. Acta Mater 1949;48.

[20] Lancaster JF. Metallurgy of welding. 5th ed. London: Chapman \& Hall; 1993.

[21] Standard practice for making and using C-ring stress corrosion test specimens. ASTM G38-01; 2001.

[22] Zalavutdinov RK, Dai Y, Gorodetsky AW, Bauer GS, Alimov VK, Zakharov AP. J Nucl Mater 2001;296:219.

[23] Pawel SJ, Manneschmidt ET. J Nucl Mater 2003;318:355.

[24] Chuang TJ, Wang ZD, Wu D. J Eng Mater Tech Trans ASME 1992;114:311.

[25] Rettenmayr M, Warkentin O, Rappaz M, Exner HE. Acta Mater 2001;49:2499.

[26] Favez D, Wagnière JD, Rappaz M. Acta Mater 2010;58:1016.

[27] Okamoto H. Phase diagrams of binary iron alloys. Materials Park (OH): ASM International; 1993.

[28] Massalski RB, editor. Binary alloy phase diagrams. Materials Park (OH): ASM International; 1987.

[29] Iijima Y, Yamazaki Y. Diffus Defect Data A 2005;237:62. 